\title{
Article \\ Coffeeberry Activates the CaMKII/CREB/BDNF Pathway, Normalizes Autophagy and Apoptosis Signaling in Nonalcoholic Fatty Liver Rodent Model
}

\author{
Meng-Chun Lu ${ }^{1,2,3}$, I-Te Lee ${ }^{4} \mathbb{D}$, Ling-Zong Hong ${ }^{5}$, Eyal Ben-Arie ${ }^{6} \mathbb{D}$, Yu-Hsuan Lin ${ }^{3}$, Wei-Ting Lin ${ }^{3}$, \\ Pei-Yu Kao ${ }^{7}$, Mei-Due Yang ${ }^{8}$ and Yin-Ching Chan ${ }^{3, *(D)}$ \\ 1 Department of Clinical Nutrition, China Medical University Hospital, Taichung 406040, Taiwan; \\ t10294@mail.cmuh.org.tw \\ 2 Department of Nutrition, China Medical University, Taichung 406040, Taiwan \\ 3 Department of Food and Nutrition, Providence University, Taichung 43301, Taiwan; \\ g1050002@gm.pu.edu.tw (Y.-H.L.); pupuki520@gmail.com (W.-T.L.) \\ 4 Division of Endocrinology and Metabolism, Taichung Veterans General Hospital, Taichung 40705, Taiwan; \\ itlee@vghtc.gov.tw \\ 5 Department of Medical Research, Taichung Veterans General Hospital, Taichung 40705, Taiwan; \\ lzhong1950@gmail.com \\ 6 Graduate Institute of Acupuncture Science, Collage of Chinese Medicine, China Medical University, \\ Taichung 406040, Taiwan; benarie19@gmail.com \\ Citation: Lu, M.-C.; Lee, I.-T.; Hong, \\ L.-Z.; Ben-Arie, E.; Lin, Y.-H.; Lin, \\ W.-T.; Kao, P.-Y.; Yang, M.-D.; Chan, \\ 7 Division of Thoracic Surgery, Department of Surgery, China Medical University Hospital, \\ Taichung 406040, Taiwan; ludouto@gmail.com \\ 8 Division of General Surgery, Department of Surgery, China Medical University Hospital, \\ Taichung 406040, Taiwan; d5218@mail.cmuh.org.tw \\ * Correspondence: ycchan@pu.edu.tw
} Y.-C. Coffeeberry Activates the CaMKII/CREB/BDNF Pathway, Normalizes Autophagy and Apoptosis Signaling in Nonalcoholic Fatty Liver Rodent Model. Nutrients 2021, 13, 3652. https://doi.org/ $10.3390 /$ nu13103652

Academic Editor: David

Cameron-Smith

Received: 3 September 2021

Accepted: 13 October 2021

Published: 19 October 2021

Publisher's Note: MDPI stays neutral with regard to jurisdictional claims in published maps and institutional affiliations.

Copyright: (c) 2021 by the authors. Licensee MDPI, Basel, Switzerland. This article is an open access article distributed under the terms and conditions of the Creative Commons Attribution (CC BY) license (https:// creativecommons.org/licenses/by/ $4.0 /)$.

\begin{abstract}
Nonalcoholic fatty liver disease (NAFLD) shows extensive liver cell destruction with lipid accumulation, which is frequently accompanied by metabolic comorbidities and increases mortality. This study aimed to investigate the effects of coffeeberry $(\mathrm{CB})$ on regulating the redox status, the CaMKII/CREB/BDNF pathway, autophagy, and apoptosis signaling by a NAFLD rodent model senescence-accelerated mice prone 8 (SAMP8). Three-month-old male SAMP8 mice were divided into a control group and three CB groups (50,100, and $200 \mathrm{mg} / \mathrm{kg} \mathrm{BW}$ ), and fed for 12 weeks. The results show that $\mathrm{CB}$ reduced hepatic malondialdehyde and carbonyl protein levels. $\mathrm{CB}$ significantly enhanced $\mathrm{Ca}^{2+}$ /calmodulin-dependent protein kinase II (CaMKII) and brain-derived neurotrophic factor (BDNF) and reduced the phospho-cAMP response element-binding protein (p-CREB)/CREB ratio. In addition, $\mathrm{CB}$ increased the silent information regulator T1 level, promoted Beclin 1 and microtubule-associated protein light chain 3 II expressions, and reduced phosphorylated mammalian target of rapamycin and its downstream p-p70s6k levels. CB also inhibited the expressions of apoptosis-related factors poly (ADP-ribose) polymerase- 1 and the apoptosis-inducing factor. In conclusion, CB might protect the liver by reducing oxidative stress, activating the CaMKII/CREB/BDNF pathway, and improving autophagic and apoptotic expressions in a dose-dependent manner.
\end{abstract}

Keywords: nonalcoholic fatty liver disease; coffeeberry; redox status; CaMKII/CREB/BDNF; autophagy; apoptosis

\section{Introduction}

With the modern western diet and the lack of exercise, nonalcoholic fatty liver disease (NAFLD) and its complications have increased worldwide, including in Asia and Taiwan. According to the Ministry of Health and Welfare report of Taiwan, chronic liver disease and liver cirrhosis were the tenth leading cause of death in 2020 [1]. Several studies on the general population and those undergoing a health checkup showed the prevalence of NAFLD ranging from $11.4 \%$ to $41 \%$ in Taiwan [2], while the estimated prevalence of 
NAFLD is $25.24 \%$ (95\% CI: $22.10-28.65$ ) worldwide [3]. Moreover, NAFLD is frequently accompanied by metabolic comorbidities, such as obesity and metabolic syndrome, and is a major cause of liver disease-related morbidity [3]. Therefore, the treatment and prevention of liver diseases, such as NAFLD, is an important issue that requires more attention.

NAFLD is mainly associated with the accumulation of fat in the liver, which causes cell lesions. Oxidative stress, lipid peroxidation, and cytokines play an important role in the NAFLD mechanism. Oxidative stress interacts with hepatic cells, resulting in degrees of hepatocyte damage, such as inflammatory responses, liver fibrosis, cirrhosis, and liver cell degeneration [4]. Recently, the CaMKII/CREB/BDNF pathway was noted to be a possibly modulatory factor associated with liver physiology. BDNF has been proven to improve fatty liver and pancreatic dysfunction in type 2 diabetic mice [5]. Chronic stress, such as inflammation, affects calcium/calmodulin-protein kinase II (CaMK II), CREB, and BDNF expression, and induces the dysfunction of calcium-ion regulation [6]. The inflammatory factors, such as iNOS, COX-2, TNF- $\alpha$, and IL- $1 \beta$, are reduced by inhibiting p-CREB expression [7]. The CaMKII/CREB/BDNF pathway may play a role in lessening the inflammatory response and retarding the accumulation of fat in the liver.

Autophagy is a lysosomal degradative pathway that functions to promote cell survival by supplying energy in stress or removing damaged organelles and proteins after injury [8]. Autophagy contributes to liver homeostasis by controlling the quality of cytoplasm, as autophagy removes misfolded proteins and damaged organelles [9]. Moreover, autophagy also shows benefits in lipid metabolism through lipophagy [10]. Lipophagy is a lysosomalautophagic pathway that plays an important part in the early steps of lipid degradation. Free fatty acids (FFAs) are generated by lipophagy, from the breakdown of triglycerides, and fuel cellular rates of mitochondrial $\beta$-oxidation [11]. Several signals are involved in modulating the autophagic function, such as the silent information regulator T1 (Sirt1), Beclin 1, and microtubule-associated protein light chain 3 II (LC3-II). Sirt1 is a nicotinamide adenine dinucleotide (NAD)-dependent class III histone deacetylase and is strongly linked to cell survival [12]. Sirt1 promotes the assembly of the autophagy-related genes (ATG) 5 and ATG12 in autophagy-related proteins by the Beclin 1 protein and increases the formation of auto-phagocytic activation index LC3-II $[13,14]$. In addition, Sirt1 also inhibits the mammalian target of rapamycin (mTOR) and its downstream P70S6K phosphorylation to enhance autophagy. mTOR is a serine/threonine-protein kinase that regulates cell metabolism, growth, proliferation, and survival [15]. Inhibited mTOR promotes the formation of the unc-51-like kinase (ULK)-1/2 complex and induces the progression of autophagy [16].

Apoptosis is another major component of programmed cell death (PCD), while an increasing number of studies support the existence of a caspase-independent pathway of PCD. Caspase-independent apoptosis is activated by oxidative stress or other factors. After activation, the poly (ADP-ribose) polymerase-1 (PARP-1) is secreted in the nucleus first, then translocates to the mitochondria and stimulates the releasing of the apoptosisinducing factor (AIF) [17]. AIF will induce the condensation and fragmentation of DNA, which eventually leads to apoptosis [17].

Coffeeberry (CB) is an unprocessed coffee bean, and shows beneficial effects on anti-oxidation, collagen production, repairing aging skin, and increasing brain-derived neurotrophic factor (BDNF) levels [18-21]. Coffeeberry extract significantly enhanced blood antioxidant capacity and prevented exercise-induced oxidative stress during training periods [22]. Polyphenol-rich, non-caffeinated coffeeberry extract beverages were also reported to significantly attenuate the scores of self-reported fatigue and alertness [23]. The livers of senescence-accelerated mice prone 8 (SAMP8) mice are characterized by increased fatty degeneration, hepatocyte death, fibrosis, cirrhotic changes, inflammatory mononuclear cell infiltration, and sporadic neoplastic changes when compared with SAMR1 mice (normal control) [24]. SAMP8 mice also showed higher alanine aminotransferase (ALT) and aspartate aminotransferase (AST) than the SAMR1 mice [24]. Thus, the SAMP8 mouse strain is suggested to be a valuable animal model for the study of liver diseases [24]. In our 
previous study, we found $\mathrm{CB}$ enhanced the liver function by lowering the inflammatory signaling factors, including nuclear factor $\mathrm{kB}(\mathrm{NF}-\mathrm{kB})$, inducible nitric oxide synthase (iNOS) and cyclooxygenase 2 (COX-2), reduced alanine aminotransferase (ALT) levels, and improved the histological changes by using SAMP8 mice [25]. However, the ability of $\mathrm{CB}$ to lessen the NAFLD process is still unclear. Thus, this study aimed to investigate the effects of CB on the related signaling of redox status, the CaMKII/CREB/BDNF pathway, autophagy, and apoptosis by using SAMP8 mice.

\section{Material and Methods}

\subsection{Animals and Diets}

SAMP8 (SAMP8/Ta Slc) mice were acquired from the Council for Senescence-Accelerated Mouse (SAM) Research, Japan, after confirming the genetic characteristics, and were maintained through inbreeding in the standard animal room at Providence University. Threemonth-old SAMP8 mice were used and divided into a control group and three different CB groups using three different doses. The control group was fed with the American Institute of Nutrition (AIN) 93-M basal diet, while the CB groups were fed the American Institute of Nutrition (AIN) 93-M basal diet mixed with CB powder with doses of 50,100, and $200 \mathrm{mg} / \mathrm{kg} \mathrm{BW} /$ day, respectively, and were allowed free access to the experimental diets and drinking water for 12 weeks ( $n=6$ /group). The mice were housed under controlled environmental conditions $\left(22 \pm 2{ }^{\circ} \mathrm{C}, 65 \% \pm 5 \%\right.$ relative humidity, 7:00-19:00 lighting period), as described in our previous study [26]. The food intake of the mice in each cage was recorded every day and the value was divided by the number of the mice in that cage to represent the mean food intake for one mouse. The weight of each mouse in each group was recorded every week until sacrifice. The study protocol was approved by the Animal Research Ethics Committee at Providence University, Taichung, Taiwan (20160607-A06 and 20170808-A0).

\subsection{Redox Status Analysis}

The liver tissue of the sacrificed mice was first separated; part of the tissue was instantly inserted into a sodium phosphate buffer (100 mM; pH 7.4), homogenized, and centrifuged at $3000 \times g$ in a refrigerated centrifuge (Hettich Universal 16 R, Tuttlingen, Germany) for $10 \mathrm{~min}$. The assembled supernatants were assessed for lipid peroxide and protein oxidation in the exact method described by Chan \& Hwang [26]. Lipid peroxidation levels were measured by blending the supernatants with $2^{\prime}$-thiobarbituric acid $(4 \mathrm{~g} / \mathrm{kg}$ in $0.2 \mathrm{M}$ of $\mathrm{HCl})$ and butylated hydroxytoluene $(2 \mathrm{~g} / \mathrm{kg}$ in $95 \%$ ethanol) at a ratio of 1:2:0.3. The blend was later heated at $90{ }^{\circ} \mathrm{C}$ for $45 \mathrm{~min}$, left to cool down, and blended with $5 \mathrm{~mL}$ of n-butanol. The n-butanol layer was detached using centrifugation $(1000 \times g$ for $10 \mathrm{~min})$ and spectrophotometrically assayed for thiobarbituric acid-reactive substances (TBARS) at $532 \mathrm{~nm}$. The results were demonstrated as $\mu$ mol equivalents of malondialdehyde (MDA) per gram of liver tissue; an MDA from tetra methoxy propane was implemented for the control. The methods of evaluating carbonyl protein levels were also identical to the methods of the Chan \& Hwang study [26]. Two $10 \mu \mathrm{L}$ of tissue sample was then placed in duplicate in $1 \mathrm{~mL}$ of phosphate buffer $\left(10 \mathrm{mM}\right.$ of $\left.\mathrm{Na}_{2} \mathrm{HPO}_{4} ; \mathrm{pH} 6.8\right)$. The two duplicates were then separated when one was treated with $0.2 \mathrm{~mL}$ of 2,4-Dinitorophenylhydrazine $(10 \mathrm{mM}$ in $2 \mathrm{~N}$ of $\mathrm{HCl}$ ), and one was treated with $0.2 \mathrm{~mL}$ of $2 \mathrm{M} \mathrm{HCl}$ and used as a blank; as a result, both samples have their own blank sample. The blend was incubated for $1 \mathrm{~h}$ at room temperature and later followed by the addition of $1.2 \mathrm{~mL}$ of $20 \%$ trichloroacetic acid. The samples were cooled down in ice for $10 \mathrm{~min}$ and later centrifuged at $2800 \mathrm{rpm}$ for $10 \mathrm{~min}$; this allowed the supernatant to be discarded. The protein pellet was washed 2 times with $3 \mathrm{~mL}$ of ethyl alcohol-ethyl acetate blend (1:1, v/v). The solvent was then discarded, and nitrogen gas was used to dry the protein pellet. $1 \mathrm{~mL}$ of sodium phosphate (pH 6.8, $10 \mathrm{mM}$ of $\mathrm{Na}_{2} \mathrm{HPO}_{4}$ containing $3 \%$ sodium dodecyl sulfate) was implemented to dissolve the protein pellet. The treated samples were compared against each sample blank in a scanner from 320 to 410 wavelengths in a spectrophotometer (Ultrospec 1100 
Pro, Amersham Biosciences, Piscataway, NJ, USA). $360 \mathrm{~nm}( \pm 10 \mathrm{~nm})$ was appointed as the peak absorbance to calculate protein carbonyl. The carbonyl groups concentration was appraised using the absorbance of $1 \mathrm{nmol} / \mathrm{mL}$ of carbonyl at $360=0.022$. The Pierce Micro BCA protein assay kit was used to conduct a protein assay assessment. The total amount of protein data was expressed as the nmol carbonyl protein formed per $\mathrm{mg}$.

\subsection{Western Blotting}

Western blotting was performed as described in our previous study [27]. The total protein samples were extracted from liver tissues, and their protein concentrations were evaluated using the bicinchoninic acid (BCA) method (Bio-Rad, Hercules, CA, USA). Protein electrophoresed on $10 \%(w / v)$ SDS polyacrylamide gels were transferred onto polyvinylidene difluoride (PVDF) membranes and blocked with TBST (TBS with $0.1 \%$ Tween-20) containing a 5\% nonfat dry milk or 5\% bovine serum albumin (BSA) for $1 \mathrm{~h}$. After blocking, membranes were kept overnight at $4{ }^{\circ} \mathrm{C}$ in a blocking solution containing different primary antibodies, including anti-CaMKII(1:1500, Cell Signaling, Danvers, MA, U SA), anti-p-CREB(1:1000, Cell Signaling, Danvers, MA, USA), anti-CREB(1:1000, Cell Signaling, Danvers, MA, USA), anti-p-CREB(1:1000, Cell Signaling, Danvers, MA, USA), anti-BDNF(1:3000, Burlingame, CA, Abcam, USA), anti-Sirt 1 (1:2000, King of Prussia, PA, CSL, USA), anti-Beclin 1 (1:3000, Irvine, California, GeneTex, USA), anti-LC3B (1:3000, Burlingame, CA, Abcam, USA), anti-mTOR(phosphor S2448) (1:3000, Burlingame, CA, Abcam, USA), anti-p-P70S6K (1:1000, King of Prussia, PA, CSL, USA), anti-AIF (1:10000, King of Prussia, PA, CSL, USA), anti-PARP 1 (1:10,000, King of Prussia, PA, CSL, USA), and anti- $\beta$ actin (1:50,000, King of Prussia, PA, CSL, USA). The membranes were exposed to secondary antibodies after being washed with TBST at room temperature for $1 \mathrm{~h}$. Immunoreactivity was detected using enhanced chemiluminescence (ECL) reagents. Quantitative results were performed using a FusionCapt Advance Camera and a FusionCapt Advance Analyzer (version 16.07, Sursee, Switzerland).

\subsection{Statistics}

The SPSS software (SPSS Inc., Chicago, IL, USA) was used to analyze the results. The main statistical test used to assess the statistical difference was the one-way analysis of variance (ANOVA). The student's t-test was used to compare the two groups in cases where the F-test was significant. Data are displayed as mean \pm standard error of mean (SEM) and the results were classified as significant if the $p$-value was lower than $0.05(p<0.05)$.

\section{Results}

\subsection{CB Reduced the Oxidative Status}

BW changes and food intakes did not differ among the four groups, while the related liver weight of three $C B$ groups tended to be lower than the control but without a significant difference (Table 1). Compared with the SAMP8 control group, 100 and $200 \mathrm{mg} / \mathrm{kg}$ BW CB groups had significantly lower lipid peroxide (Figure 1A). Furthermore, the $200 \mathrm{mg} / \mathrm{kg}$ BW CB group had significantly decreased carbonyl protein levels (Figure 1B). These results reveal that $C B$ could reduce oxidative stress in the NAFLD animal model.

Table 1. Body weight gains, food intakes, and relative liver weight of 3-month-old male SAMP8 mice fed with different diet for 12 weeks.

\begin{tabular}{ccccc}
\hline Group & N & $\begin{array}{c}\text { Weight Gain } \\
\text { (gm) }\end{array}$ & $\begin{array}{c}\text { Food Intakes } \\
\text { (gm/day) }\end{array}$ & $\begin{array}{c}\text { Liver } \\
\text { (g/100g Body Weight) }\end{array}$ \\
\hline A & 6 & $3.08 \pm 0.43$ & $7.83 \pm 0.16$ & $4.36 \pm 0.15$ \\
B & 6 & $3.41 \pm 0.32$ & $7.51 \pm 0.17$ & $4.21 \pm 0.20$ \\
C & 6 & $3.42 \pm 0.35$ & $7.73 \pm 0.49$ & $4.20 \pm 0.19$ \\
D & 6 & $3.33 \pm 0.38$ & $7.69 \pm 0.28$ & $4.25 \pm 0.13$ \\
\hline
\end{tabular}

Values are displayed as mean \pm S.E.M. and were analyzed by one-way ANOVA. A = SAMP8 control, B = 50 mg $/ \mathrm{kg}$ $\mathrm{BW} /$ day $\mathrm{CB}, \mathrm{C}=100 \mathrm{mg} / \mathrm{kg} \mathrm{BW} /$ day $\mathrm{CB}, \mathrm{D}=200 \mathrm{mg} / \mathrm{kg} \mathrm{BW} /$ day CB. 
(A)

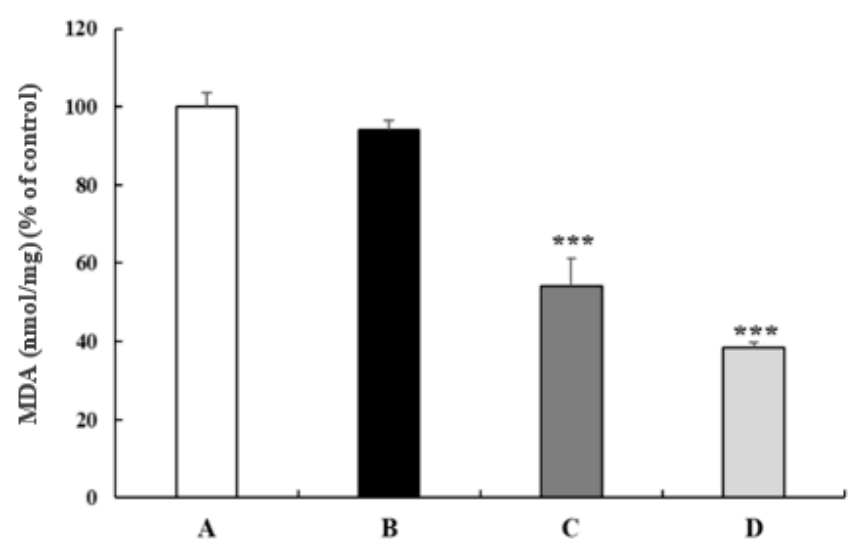

(B)

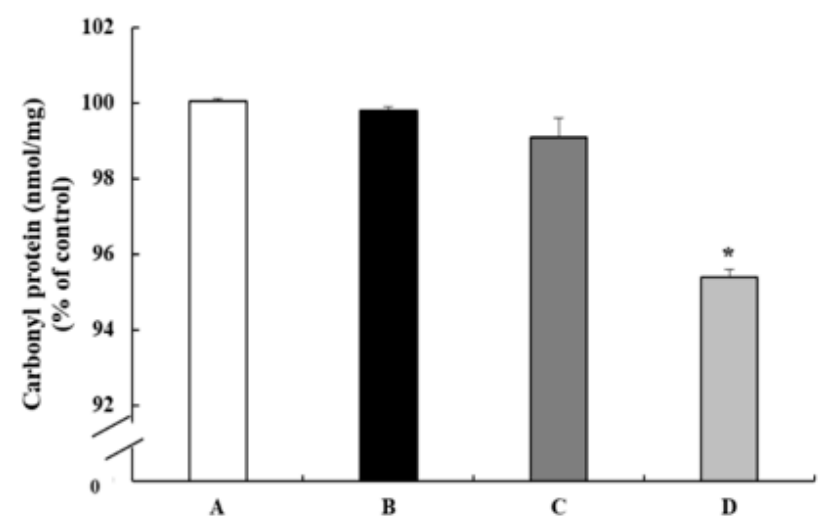

Figure 1. The (A) MDA and (B) carbonyl protein levels in the livers of 3-month-old male SAMP8 mice fed with different diets for 12 weeks. Values are displayed as mean \pm S.E.M. and were analyzed by one-way ANOVA ( $n=6 /$ group). ${ }^{*} p<0.05$, *** $p<0.001$ compared to the control group. A = SAMP8 control, B= $50 \mathrm{mg} / \mathrm{kg}$ BW/day CB, C = $100 \mathrm{mg} / \mathrm{kg}$ BW/day CB, $\mathrm{D}=200 \mathrm{mg} / \mathrm{kg} \mathrm{BW} /$ day CB.

\subsection{CB Improved the CaMKII/CREB/BDNF Signaling}

Three-month-old SAMP8 mice were administered CB $(50 \mathrm{mg} / \mathrm{kg}$ BW, $100 \mathrm{mg} / \mathrm{kg}$ BW, $200 \mathrm{mg} / \mathrm{kg} \mathrm{BW}$ ). After 12 weeks of administration, liver lysates were immunoblotted with targeted antibodies. Compared to the control group, the 100 and $200 \mathrm{mg} / \mathrm{kg}$ BW CB groups had significantly increased BDNF expression and a lower $\mathrm{p}$-CREB/CREB ratio (Figure 2B,C). The CAMKII levels of the three CB groups tended to be higher than those of the control group, while the significance was found only between the control and the $100 \mathrm{mg} / \mathrm{kg}$ BW group (Figure 2D). These data suggested that CB affected the expressions of CaMKII/CREB/BDNF signaling.

\subsection{CB Enhanced the Autophagic Expressions}

Compared with the control group, the $200 \mathrm{mg} / \mathrm{kg}$ BW CB group had increased Sirt 1 expression (Figure $3 \mathrm{~B}$ ). The Beclin 1 and LC3-II protein expressions in the liver are shown in Figure 3C,D, respectively. Compared to the control group, 100 and $200 \mathrm{mg} / \mathrm{kg}$ BW CB supplementations significantly increased Beclin 1 expression, whereas only the $200 \mathrm{mg} / \mathrm{kg}$ BW CB group had significantly higher LC3-II expression than the control group. Figure $3 \mathrm{E}, \mathrm{F}$ showed the $\mathrm{p}-\mathrm{mTOR}$ and $\mathrm{p}$-P70S6K protein expressions in the liver. The 100 and $200 \mathrm{mg} / \mathrm{kg}$ BW CB groups had significantly decreased p-mTOR expressions compared to the control group. In addition, the $200 \mathrm{mg} / \mathrm{kg}$ BW CB group had lower p-P70S6K expression than the other three groups. The above results indicate that $\mathrm{CB}$ increased the autophagy in a dose-dependent manner by enhancing Beclin 1 and LC3-II expressions via inhibiting the expressions of $\mathrm{p}-\mathrm{mTOR}$ and $\mathrm{p}-\mathrm{P} 70 \mathrm{~S} 6 \mathrm{~K}$ protein. 
(A)

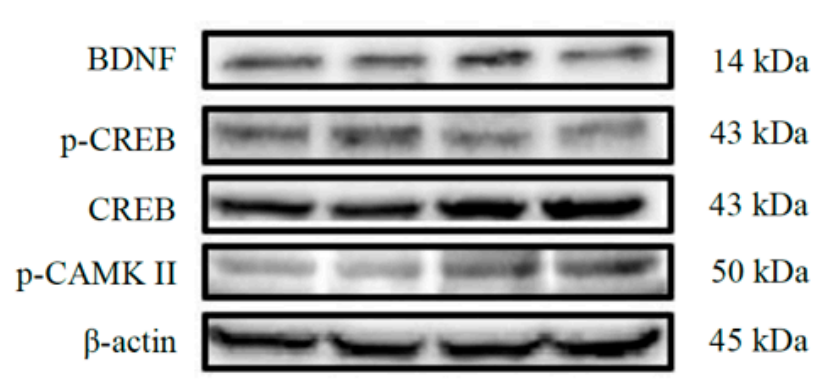

(C)

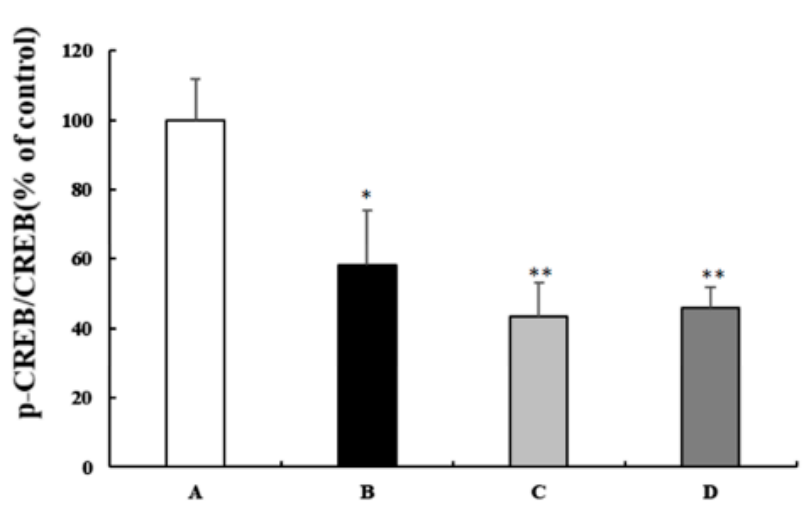

(B)

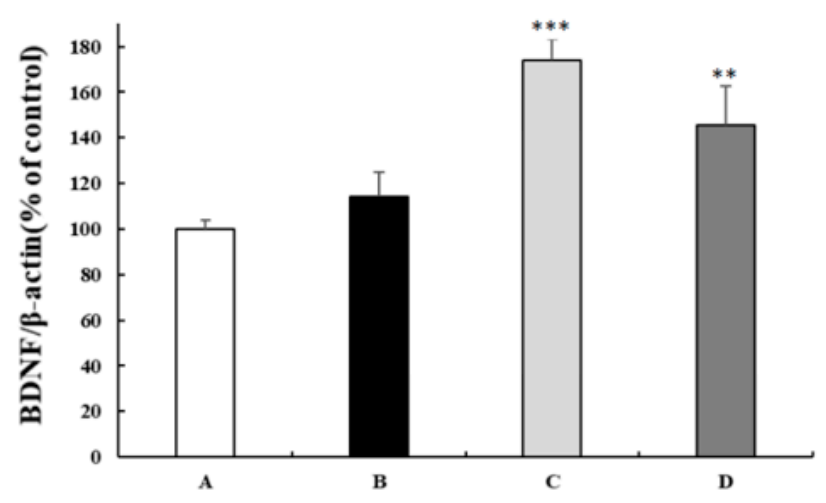

(D)

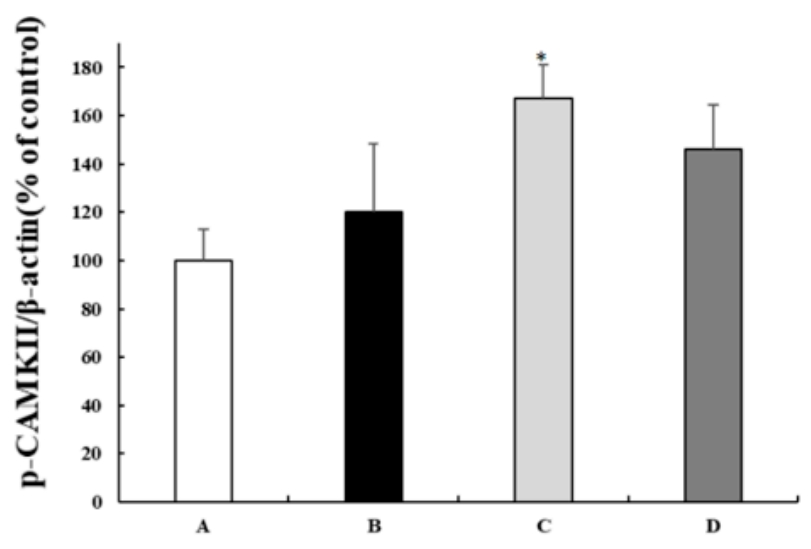

Figure 2. Protein expressions of the livers in 3-month-old male SAMP8 mice fed with different diets for 12 weeks. (A) The gel picture BDNF, p-CREB, total CREB, p-CAMK II, and $\beta$-actin expressions. (B) BDNF, (C) p-CREB/total CREB ratio, and (D) p-CAMK II expressions of the liver among different groups. The y axis quantified by the western blot analysis protein of BDNF/ $\beta$-actin, $\mathrm{p}$-CREB/CREB ratio, and $\mathrm{p}$-CAMKII/ $\beta$-actin are expressed as the percentage of control. Values are displayed as mean \pm S.E.M. and were analyzed by one-way ANOVA $\left(n=6 /\right.$ group). ${ }^{*} p<0.05,{ }^{* *} p<0.005,{ }^{* * *} p<0.001$ compared to the control group. A = SAMP8 control, B $=50 \mathrm{mg} / \mathrm{kg} \mathrm{BW} /$ day CB, C $=100 \mathrm{mg} / \mathrm{kg} \mathrm{BW} /$ day CB, D = 200 mg/kg $\mathrm{BW} /$ day $\mathrm{CB}$.

\subsection{CB Inhibited the Caspase-Independent Apoptosis}

In this study, we also evaluated the effects of $\mathrm{CB}$ on the caspase-independent apoptotic factors. When compared with the SAMP8 control group, the 100 and $200 \mathrm{mg} / \mathrm{kg}$ BW CB groups showed a significantly lower cleaved-PARP 1 and cleaved-PARP 1/PARP 1 ratio (Figure $4 B, C$ ). Furthermore, the $200 \mathrm{mg} / \mathrm{kg}$ BW CB group had significantly reduced AIF expression when compared to the control group (Figure $4 \mathrm{D}$ ). These data suggest that $\mathrm{CB}$ enhanced the apoptosis reaction by downregulating the PARP 1 and AIF expressions. 
(A)

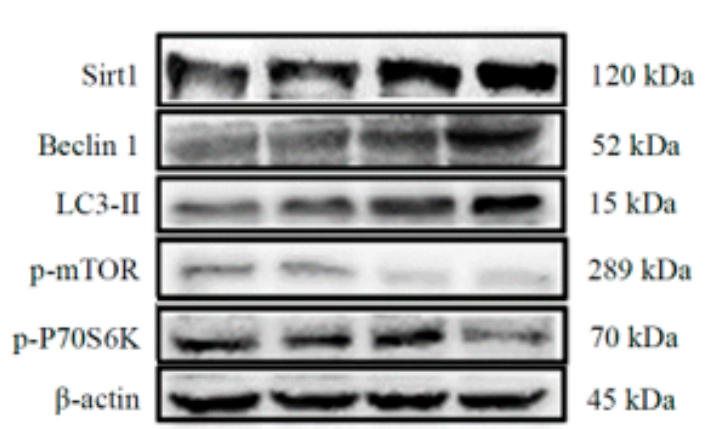

(C)

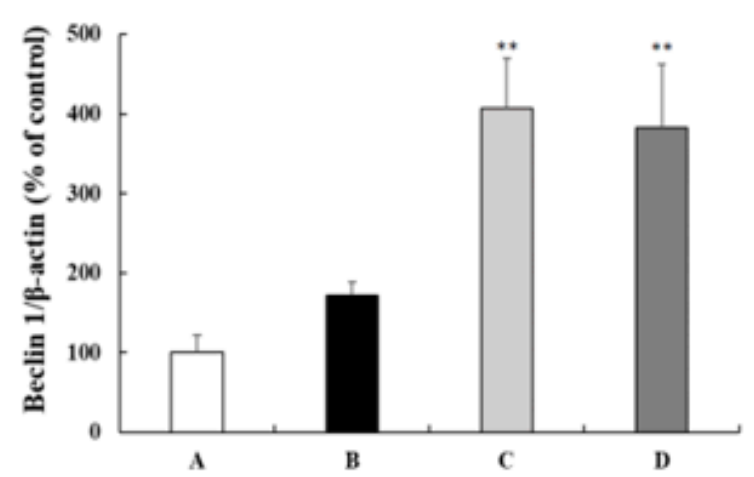

(E)

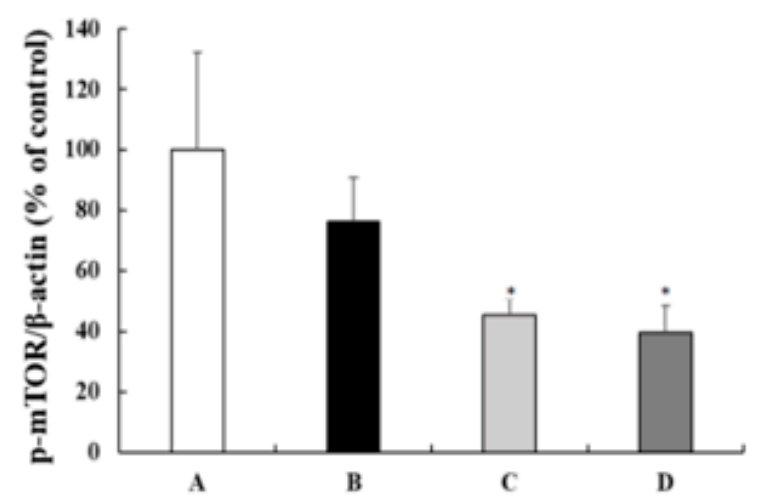

(B)

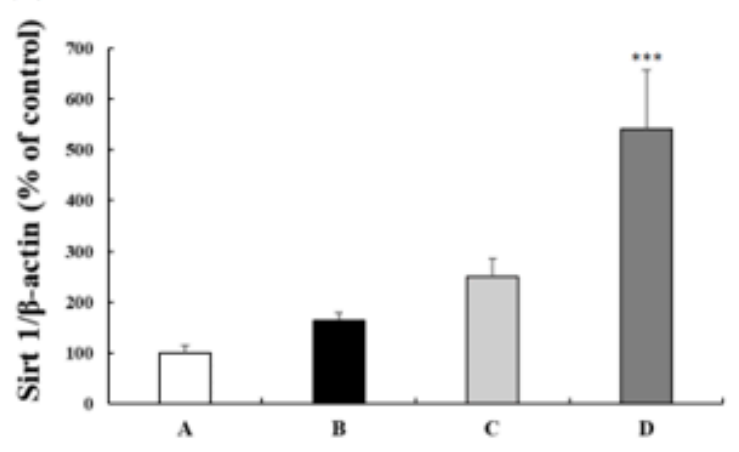

(D)

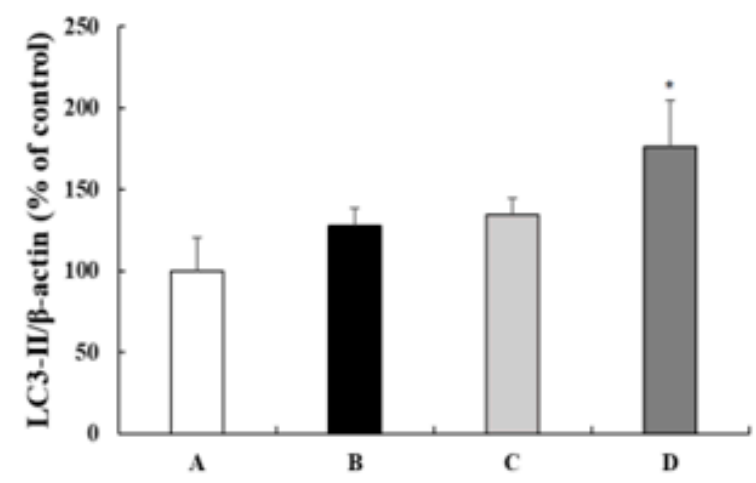

(F)

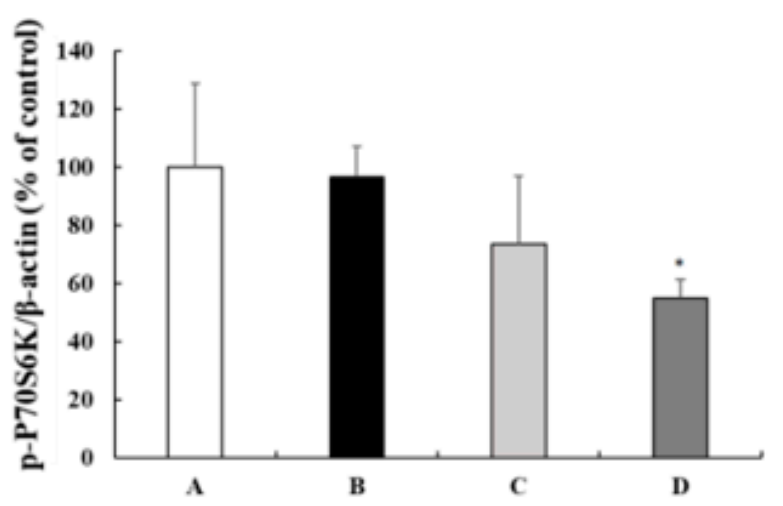

Figure 3. Protein expressions in the livers of 3-month-old male SAMP8 mice fed with different diets for 12 weeks. (A) The gel picture of Sirt 1, Beclin 1, LC3-II, p-mTOR, p-P70S6K, and $\beta$-actin expressions. (B) Sirt 1, (C) Beclin 1, (D) LC3-II, (E) p-mTOR, and (F) p-P70S6K protein expression in the livers of different groups. The y axis quantified by the western blot analysis protein of Sirt $1 / \beta$-actin, Beclin $1 / \beta$-actin, LC3-II/ $\beta$-actin, $\mathrm{p}$-mTOR/ $\beta$-actin, and $\mathrm{p}$-P70S6K/ $\beta$-actin are expressed as the percentage of control. Values are displayed as mean \pm S.E.M. and were analyzed by one-way ANOVA ( $n=6 /$ group). ${ }^{*} p<0.05,{ }^{* *} p<0.005,{ }^{* * *} p<0.001$ compared to the control group. A $=$ SAMP8 control, B $=50 \mathrm{mg} / \mathrm{kg} \mathrm{BW} /$ day CB, $\mathrm{C}=100 \mathrm{mg} / \mathrm{kg} \mathrm{BW} /$ day $\mathrm{CB}, \mathrm{D}=200 \mathrm{mg} / \mathrm{kg} \mathrm{BW} /$ day CB. 
(A)

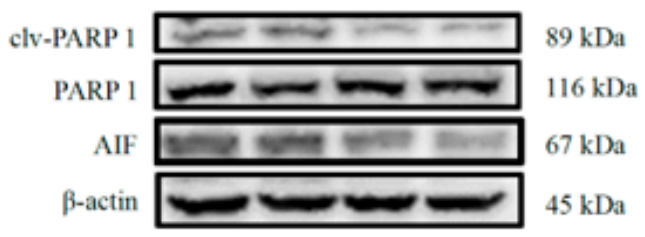

(C)

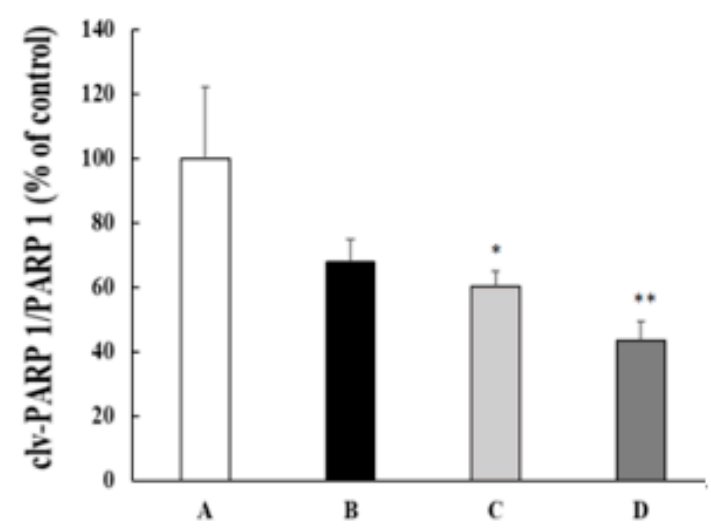

(B)

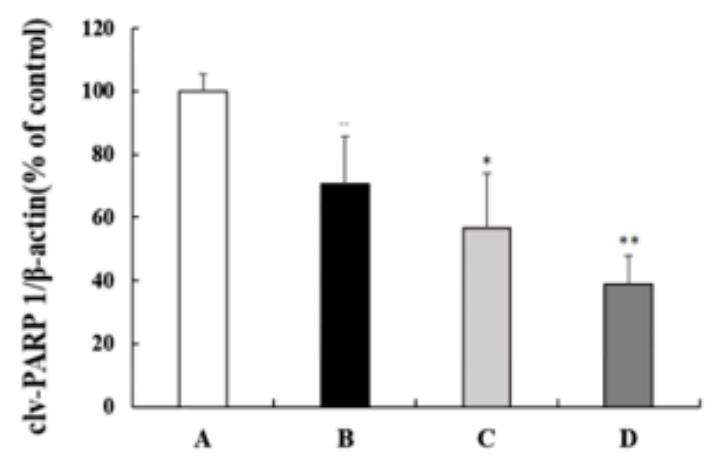

(D)

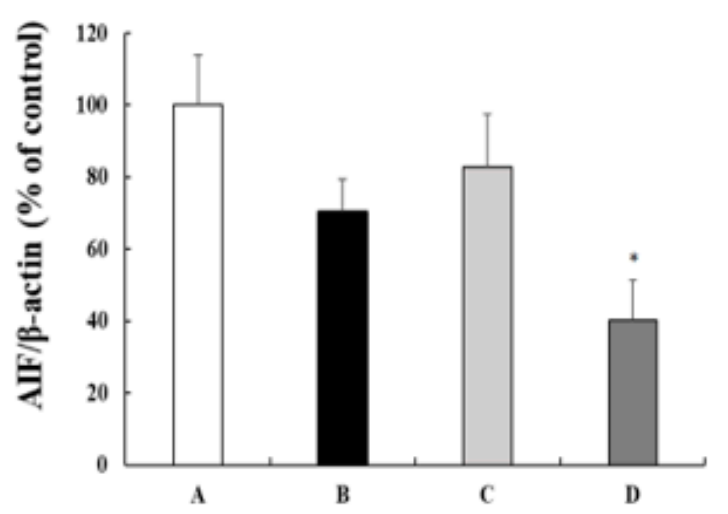

Figure 4. Protein expressions in the livers of 3-month-old male SAMP8 mice fed with different diets for 12 weeks. (A) The gel picture of cleaved-PARP 1, PARP 1, AIF, and $\beta$-actin expressions. (B) cleaved-PARP 1, (C) cleaved-PARP 1/PARP 1 ratio, and (D) AIF protein expression in livers of different groups. The y axis quantified by the western blot analysis protein of cleaved-PARP $1 / \beta$-actin, cleaved-PARP $1 /$ PARP 1 ratio, and AIF/ $\beta$-actin, expressed as the percentage of control. Values are displayed as mean \pm S.E.M. and were analyzed by one-way ANOVA ( $n=6 /$ group). ${ }^{*} p<0.05,{ }^{* *} p<0.005$ compared to the control group. A = SAMP8 control, B = $50 \mathrm{mg} / \mathrm{kg} \mathrm{BW} /$ day CB, C = $100 \mathrm{mg} / \mathrm{kg} \mathrm{BW} /$ day CB, D = $200 \mathrm{mg} / \mathrm{kg} \mathrm{BW} / \mathrm{day}$ CB.

\section{Discussion}

Our previous study showed that CB reduced ALT level and improved the fatty liver score of SAMP8 mice by lowering the inflammatory signaling [25]. The present study further demonstrated that CB reduced the hepatic oxidative stress, enhanced CaMKII/CREB/ BDNF and autophagic signaling, and inhibited the caspase-independent apoptosis. These results indicate $\mathrm{CB}$ as a potential agent for lessening the damage in liver disorder.

CaMKII/CREB/BDNF signaling is linked with cognitive and learning functions [28]. CaMKII phosphorylation activates signaling molecules and several other transcription factors including CREB [29], while CREB is associated with memory and synaptic plasticity that binds to the promoter regions of many genes [30]. Reduced intracellular p-CaMKII increases the intracellular CREB and p-CREB expression in the hippocampus, resulting in improved nuclear transcription activities of CREB [31]. CREB further alters the expression of BDNF, and BDNF is noted to play crucial roles in the nervous systems by promoting neurons differentiation, improving neurite outgrowth and synaptogenesis, and inhibiting apoptosis [32]. A study by Islam et al. [28] demonstrated that the oral administration of Theobromine, a primary methylxanthine found in cacao beans, improved the working memory by the upregulation of p-CaMKII, p-CREB, and BDNF levels. This indicates the importance of CaMKII/CREB/BDNF signaling in neuroprotection. However, the implicate of CaMKII/CREB/BDNF signaling on liver tissue, especially in liver disorder, is not clear yet. 
A data-mining analysis revealed that BDNF is an important marker for the prevention and treatment of NAFLD [33]. BDNF level is significantly lower in patients with liver cirrhosis induced by hepatitis B virus (HBV) [34]. In the high-fat diet- (HFD) fed-mice, hepatic steatosis is induced by reducing the BDNF-TrkB expression [35]. Genzer et al. [36] investigated the comprehensive metabolic analysis of BDNF signaling in hepatocytes. The study demonstrated that BDNF treatment decreased CREB and GS3K proteins to inhibit gluconeogenesis and activate glycogen synthesis. In hepatocytes, CREB is a downstream target of BDNF, which is an endonuclear regulatory factor, regulating transcription by self-phosphorylation. CREB plays an important role in gluconeogenesis and fatty acid oxidation [37] and has been proven to reduce hepatic TG synthesis and storage during fasting via PPAR- $\gamma$ repression [38]. The phosphorylation of CREB increases CAMK-II expression and then inhibits the proliferation of activated hepatic stellate cells [39]. Inhibited CaMKII expression reduces the phosphorylation of FoxO1, which leads the impairments of hepatic glucose homeostasis [40]. Our results found that the CB groups have significantly increased BDNF and CaMKII levels and reduced CREB expression. This indicates that the CaMKII/CREB/BDNF pathway is an important factor to modulate the physiological status of the liver.

On the other hand, autophagy is also reported to ameliorate the pathogenesis of NAFLD by lowering the hepatic lipid load by lipophagy [41]. In the NAFLD rat model, autophagy-related proteins LC3 and Beclin1 are significantly decreased at both the mRNA and protein levels [42]. HFD-induced obese mice also show reduced hepatic autophagic function reflected in reduced Beclin-1 and LC3-II levels and decreased numbers of autophagosomes/autolysosomes [43]. Nonalcoholic steatohepatitis (NASH) patients have higher LC3-II, while the LC3-II level positively associates with the severity of liver disease. In addition, Sirt1 is proven to promote the expression of Beclin 1 and lead to the increase in auto-phagocytic activation index LC3-II $[13,14]$. Resveratrol improves hepatic steatosis by mediating the Sirt1/activating transcription factor 6 dependent mechanism [44]. Calorie restriction improves the NAFLD by enhancing the Sirt1 expression [45]. The above evidence indicates that autophagy plays a protective role during NAFLD. In this study, our results show that the supplementation of CB-enhanced Sirt1 expression promoted the formation of autophagosomes transformed by enhancing Belin 1 expression and increased the performance of autophagy marker protein LC3-II. Furthermore, Sirt1 also enhanced autophagy by inhibiting the phosphorylation of mTOR and its downstream P70S6K.

mTOR plays a key role in the regulation of lysosomal and autophagic acidification through the modulation of V-ATPase expression, and its use as an indicator to evaluate autophagic dysfunction in NAFLD has been suggested [46]. Autophagy occurs via the activation of mTOR signaling, contributing to its protective effects on liver ischemia/reperfusion injury [47]. Phytochemical may also achieve beneficial effects on hepatic protection by modulating the autophagic reaction. Coffee consumption is reported to decrease hepatic p-mTOR levels in aged mice [48]. Many studies have investigated the possible molecular mechanisms regarding coffee's role in liver protection, most of them indicating the importance of caffeine and chlorogenic acid on lessening liver fibrosis [49]. Furthermore, caffeine and chlorogenic acid are also the active components in whole coffee fruit extract [50]. Caffeine is noted to enhance autophagic reaction via reducing PI3K/Akt/mTOR/p70S6K signaling [51]. Caffeine also increases the autophagy flux in hepatic stellate cells through the IRE1- $\alpha$ signaling pathway and inhibits the activation of hepatic astrocyte by blocking adenosine receptors in the experimental fibrosis model [49]. Chlorogenic acid is reported to enhance the sensitivity of human hepatocellular carcinoma cells lines to regorafenib treatment by inhibiting PI3K/Akt/mTOR signaling [52] and lessening liver injury by inhibiting autophagy in a rat model of NAFLD [53]. In this study, the supplementation of CB enhanced Sirt1 expression, promoted the formation of autophagosomes transformed by Belin 1 protein expression, and increased the performance of autophagy marker protein LC3-II. Increased Sirt1 expression also downregulated the phosphorylation of p-mTOR and 
its downstream P70S6K. This evidence indicates the beneficial effects of CB in enhancing the autophagic reactions in the livers of SAMP8 mice.

PARP-1, AIF, and endonuclease G (EndoG) play key roles in the caspase-independent apoptosis signaling pathway. Oxidative stress stimulates the nucleus to secrete PARP-1 and translocate to the mitochondria and promotes the AIF or Endo G on the mitochondria membrane to be released into the cytoplasm and nucleus, causing DNA condensation and fragmentation, leading to apoptosis [17]. PARP1 is activated in the non-alcoholic fatty liver of mice and patients. Inhibition of PARP1 activation reduces lipid accumulation and the inflammation of fatty liver in mice [54]. PARP inhibitors are noted to reduce hepatic triglyceride accumulation, metabolic disorders, inflammation, and fibrosis in preclinical models of liver disease [55]. PARP inhibitors also attenuate PARP activation and retard the development of liver damage in hepatitis models, and these benefits are related to Sirt1 [56]. Caffeine is noted to lower the survival of hepatic stellate cells (HSCs) by inducing apoptosis reaction [57]. Caffeine combined with 5-FU significantly increases the apoptotic level by up-regulating cleaved PARP and down-regulating Bcl-2 and Bcl-xL expressions in hepatocellular carcinoma (HCC) cells [58]. Caffeine induces glioma cell death, possibly via elevating the cleaved PARP-1/PARP-1 ratio and AIF expression [59]. Chlorogenic acid protects primary rat hepatocytes against palmitic acid-induced damage by reducing ER stress-mediated apoptosis [60] and prevents liver fibrosis and hepatoma by reducing oxidative pressure and modulating the homeostasis of glucose and lipids [49]. Our results demonstrate that CB supplementation increased Sirt 1 expression in a dose-dependent manner and reduced the levels of cleaved-PARP 1, cleaved-PARP 1/PARP 1 ratio, and AIF in the liver. These results show that upregulated Sirt1 expression may inhibit apoptosis by reducing PARP 1 and AIF releases.

Coffeeberry is derived from the whole fruit of the coffee plant, which contains valuable ingredients and has the potential to enhance nutrition and health, including antioxidant capacity, immune regulation, and tumor suppression [61]. CB has higher free-radical scavenging activity when compared with vitamin $C$ or vitamin E [62]. Whole coffee fruit extract is proven to have great antioxidant properties with its high polyphenols, such as caffeine, chlorogenic acid, condensed proanthocyanidins, quinic acid, and ferulic acid [50]. The anti-obesity influence of coffee fruit extract may be due to its anti-adipogenic and lipolytic properties in 3T3-L1 adipocytes [63]. Coffee supplementation significantly reduces glutathione disulfide and MDA levels in the HFD diet group [64]. Caffeine, one component of $\mathrm{CB}$, is consecutively metabolized in the liver into potentially active compounds by cytochrome P450 isoform CYP1A2, N-acetyl-transferase type 2, and xanthine oxidase [65], and has beneficial effects on inhibiting lipid peroxidation [66] and lowering the glutamyltransferase levels [67]. In addition, caffeine stimulates hepatic fat oxidation and shows potential lipolysis advantages in the NAFLD model through autophagy and significantly reduces hepatosteatosis through increasing liver $\beta$-oxidation, lipid uptake, and enhancing LC3-II and autophagic flux levels [68]. Our previous study demonstrated that CB lowered the ALT level, decreased the iNOS and COX-2 expressions, and improved fatty liver scores in SAMP8 mice [25]. In this study, we further found that CB lowered hepatic lipid peroxide and carbonyl protein levels, enhanced the CaMKII/CREB/BDNF and autophagic signaling, and reduced the apoptosis in a dose-dependent manner. However, the effective ingredients of CB in lessening liver disorder need further study.

We are the first to investigate the possible mechanism of CB by using a NAFLD rodent model. Our results reveal that $C B$ supplementation reduced oxidative damage in the livers of SAMP8 mice, possibly through improving the CaMKII/CREB/BDNF pathway and autophagic signaling and downregulating the apoptosis factors. This evidence supports the potential benefits of $\mathrm{CB}$ in lessening the pathological progress of NAFLD.

Author Contributions: Conceptualization, Y.-C.C.; data curation, L.-Z.H., and E.B.-A.; funding acquisition, Y.-C.C.; project administration, M.-C.L., I.-T.L., Y.-H.L. and W.-T.L.; supervision, M.-D.Y. and Y.-C.C.; writing-original draft, M.-C.L., E.B.-A., P.-Y.K. and Y.-C.C.; writing-review \& editing, Y.-C.C. All authors have read and agreed to the published version of the manuscript. 
Funding: This work was supported by grants from China Medical University Hospital, Taiwan (DMR-106-111 and DMR-107-102), Taichung Veterans General Hospital, Providence University (TCVGH-PU1058001 and TCVGH-PU1068102), Taichung, Taiwan, and in part by the Ministry of Science and Technology (MOST), Taiwan (MOST 108-2320-B-126-002-MY3).

Institutional Review Board Statement: The study was conducted according to the guidelines of the Animal Protection Act of Taiwan, and approved by the Animal Research Ethics Committee at Providence University, Taichung, Taiwan (protocol code 20160607-A06 and 20170808-A0, which were approved on 20160607 and 20170808, respectively).

Informed Consent Statement: Not applicable.

Data Availability Statement: Not applicable.

Acknowledgments: We are grateful to the Council for Senescence-Accelerated Mouse (SAM) Research, Japan, for supplying the SAMP8 mice, and Lytone Enterprise, Inc., Taiwan, for providing the CB sample.

Conflicts of Interest: The authors declare no conflict of interest.

\section{References}

1. Ministry of Health and Welfare. 2020. Available online: https://www.mohw.gov.tw/mp-1.html (accessed on 12 October 2021).

2. Hsu, C.S.; Kao, J.H. Non-alcoholic fatty liver disease: An emerging liver disease in Taiwan. J. Formos. Med. Assoc. 2012, 111, 527-535. [CrossRef] [PubMed]

3. Younossi, Z.M.; Koenig, A.B.; Abdelatif, D.; Fazel, Y.; Henry, L.; Wymer, M. Global epidemiology of nonalcoholic fatty liver disease-Meta-analytic assessment of prevalence, incidence, and outcomes. Hepatology 2016, 64, 73-84. [CrossRef] [PubMed]

4. Chen, S.; Teoh, N.C.; Chitturi, S.; Farrell, G.C. Coffee and non-alcoholic fatty liver disease: Brewing evidence for hepatoprotection? J. Gastroenterol. Hepatol. 2014, 29, 435-441. [CrossRef] [PubMed]

5. Yamanaka, M.; Itakura, Y.; Tsuchida, A.; Nakagawa, T.; Noguchi, H.; Taiji, M. Comparison of the antidiabetic effects of brainderived neurotrophic factor and thiazolidinediones in obese diabetic mice. Diabetes Obes. Metab. 2007, 9, 879-888. [CrossRef] [PubMed]

6. Vásquez, C.E.; Riener, R.; Reynolds, E.; Britton, G.B. NMDA receptor dysregulation in chronic state: A possible mechanism underlying depression with BDNF downregulation. Neurochem. Inter. 2014, 79, 88-97. [CrossRef]

7. Zong, Y.; Sun, L.; Liu, B.; Deng, Y.S.; Zhan, D.; Chen, Y.L.; He, Y.; Liu, J.; Zhang, Z.J.; Sun, J.; et al. Resveratrol inhibits LPS-induced MAPKs activation via activation of the phosphatidylinositol 3-kinase pathway in murine RAW 264.7 macrophage cells. PLoS ONE 2012, 7, e44107. [CrossRef]

8. Czaja, M.J. Function of autophagy in nonalcoholic fatty liver disease. Dig. Dis. Sci. 2016, 61, 1304-1313. [CrossRef]

9. Komatsu, M.; Waguri, S.; Ueno, T.; Iwata, J.; Murata, S.; Tanida, I.; Ezaki, J.; Mizushima, N.; Ohsumi, Y.; Uchiyama, Y.; et al. Impairment of starvation-induced and constitutive autophagy in Atg7-deficient mice. J. Cell Biol. 2005, 169, 425-434. [CrossRef]

10. Singh, R.; Kaushik, S.; Wang, Y.; Xiang, Y.; Novak, I.; Komatsu, M.; Tanaka, K.; Cuervo, A.M.; Czaja, M.J. Autophagy regulates lipid metabolism. Nature 2009, 458, 1131-1135. [CrossRef]

11. Liu, K.; Czaja, M.J. Regulation of lipid stores and metabolism by lipophagy. Cell Death Differ. 2013, 20, 3-11. [CrossRef]

12. Alcendor, R.R.; Gao, S.; Zhai, P.; Zablocki, D.; Holle, E.; Yu, X.; Tian, B.; Wagner, T.; Vatner, S.F.; Sadoshima, J. Sirt1 regulates aging and resistance to oxidative stress in the heart. Circ. Res. 2007, 100, 1512-1521. [CrossRef]

13. Rubinsztein, D.C.; Cuervo, A.M.; Ravikumar, B.; Sarkar, S.; Korolchuk, V.I.; Kaushik, S.; Klionsky, D.J. In search of an autophagomometer. Autophagy 2009, 5, 585-589. [CrossRef]

14. Zhenhua, L.; Jian, W.; Xiao, Y. Functions of autophagy in pathological cardiac hypertrophy. Int. J. Biol. Sci. 2015, 11, 672-678.

15. Laplante, M.; Sabatini, D.M. mTOR signaling at a glance. J. Cell Sci. 2009, 122, 3589-3594. [CrossRef] [PubMed]

16. Abounit, K.; Scarabelli, T.M.; McCauley, R.B. Autophagy in mammalian cells. J. Biol. Chem. 2012, 3, 1-6. [CrossRef] [PubMed]

17. Wang, Y.; Dawson, V.L.; Dawson, T.M. Poly(ADP-ribose) signals to mitochondrial AIF: A key event in parthanatos. Exp. Neurol. 2009, 218, 193-202. [CrossRef] [PubMed]

18. Ostojic, S.M.; Stojanovic, M.D.; Djordjevic, B.; Jourkesh, M.; Vasiljevic, N. The effects of a 4-week coffeeberry supplementation on antioxidant status, endurance, and anaerobic performance in college athletes. Sports Med. 2008, 16, 281-294. [CrossRef] [PubMed]

19. McDaniel, D.H. Clinical safety and efficacy in photoaged skin with coffeeberry extract, a natural antioxidant. J. Cosmet. Dermatol. 2009, 22, 610-616.

20. Reyes-Izquierdo, T.; Nemzer, B.; Shu, C.; Huynh, L.; Argumedo, R.; Keller, R.; Pietrzkowski, Z. Modulatory effect of coffee fruit extract on plasma levels of brain-derived neurotrophic factor in healthy subjects. Br. J. Nutr. 2013, 110, 420-425. [CrossRef]

21. Suggs, A.; Oyetakin-White, P.; Baron, E.D. Effect of botanicals on inflammation and skin aging: Analyzing the evidence. Inflamm. Allergy Drug Targets 2014, 13, 168-176. [CrossRef]

22. Ostojic, S.M.; Stojanovic, M.D.; Djurovic, D. The effects of coffeeberry extract on plasma total phenolic content and antioxidant capacity in physically active men. Sci. Sports 2012, 27, 308-311. [CrossRef] 
23. Reed, R.A.; Mitchell, E.S.; Saunders, C.; O'Connor, P.J. Acute low and moderate doses of a caffeine-free polyphenol-rich coffeeberry extract improve feelings of alertness and fatigue resulting from the performance of fatiguing cognitive tasks. J. Cogn. Neurosci. 2019, 3, 193-206. [CrossRef]

24. Ye, X.; Meeker, H.C.; Kozlowski, P.B.; Wegiel, J.; Wang, K.C.; Imaki, H.; Carp, R.I. Pathological changes in the liver of a senescenceaccelerated mouse strain (SAMP8): A mouse model for the study of liver diseases. Histol. Histopathol. 2004, 19, $1141-1151$. [PubMed]

25. Lu, M.C.; Wu, C.S.; Yang, M.D.; Wang, M.F.; Chan, Y.C. Effects of coffeeberry on fatty liver and related inflammatory factors. Taiwan. J. Agric. Chem. Food Sci. 2020, 58, 1-9.

26. Chan, Y.C.; Hwang, J.H. Effects of Spirulina on the functions and redox status of auditory system in senescence-accelerated prone-8 mice. PLoS ONE 2017, 12, e0178916. [CrossRef] [PubMed]

27. Chan, Y.C.; Wu, C.S.; Wu, T.C.; Lin, Y.H.; Chang, S.J. A Standardized extract of Asparagus officinalis Stem (ETAS ${ }^{\circledR}$ ) ameliorates cognitive impairment, inhibits amyloid $\beta$ deposition via BACE-1 and normalizes circadian rhythm signaling via MT1 and MT2. Nutrients 2019, 11, 1631. [CrossRef] [PubMed]

28. Islam, R.; Matsuzaki, K.; Sumiyoshi, E.; Hossain, M.E.; Hashimoto, M.; Katakura, M.; Sugimoto, N.; Shido, O. Theobromine improves working memory by activating the CaMKII/CREB/BDNF pathway in rats. Nutrients 2019, 11, 888. [CrossRef]

29. Sheng, M.; Thompson, M.A.; Greenberg, M.E. CREB: A Ca ${ }^{(2+)}$-regulated transcription factor phosphorylated by calmodulindependent kinases. Science 1991, 252, 1427-1430. [CrossRef]

30. Barco, A.; Bailey, C.H.; Kandel, E.R. Common molecular mechanisms in explicit and implicit memory. J. Neurochem. 2006, 97, 1520-1533. [CrossRef] [PubMed]

31. Xie, W.; Meng, X.; Zhai, Y.; Ye, T.; Zhou, P.; Nan, F.; Sun, G.; Sun, X. Antidepressant-like effects of the Guanxin Danshen formula via mediation of the CaMK II-CREB-BDNF signalling pathway in chronic unpredictable mild stress-induced depressive rats. Ann. Transl. Med. 2019, 7, 564. [CrossRef]

32. Chao, M.V.; Rajagopal, R.; Lee, F.S. Neurotrophin signalling in health and disease. Clin. Sci. 2006, 110, 167-173. [CrossRef]

33. Hashida, R.; Nakano, D.; Yamamura, S.; Kawaguchi, T.; Tsutsumi, T.; Matsuse, H.; Torimura, T. Association between activity and brain-derived neurotrophic factor in patients with non-alcoholic fatty liver disease: A data-mining analysis. Life 2021, 11, 799. [CrossRef] [PubMed]

34. Shu, H.C.; Hu, J.; Jiang, X.B.; Deng, H.Q.; Zhang, K.H. BDNF gene polymorphism and serum level correlate with liver function in patients with hepatitis B-induced cirrhosis. Int. J. Clin. Exp. Pathol. 2019, 12, 2368-2380. [PubMed]

35. Camer, D.; Yu, Y.; Szabo, A.; Dinh, C.H.; Wang, H.; Cheng, L.; Huang, X.F. Bardoxolone methyl prevents insulin resistance and the development of hepatic steatosis in mice fed a high-fat diet. Mol. Cell Endocrinol. 2015, 412, 36-43. [CrossRef] [PubMed]

36. Genzer, Y.; Chapnik, N.; Froy, O. Effect of brain-derived neurotrophic factor (BDNF) on hepatocyte metabolism. Int. J. Biochem. Cell Biol. 2017, 88, 69-74. [CrossRef]

37. Herzig, S.; Long, F.; Jhala, U.S.; Hedrick, S.; Quinn, R.; Bauer, A.; Rudolph, D.; Schutz, G.; Yoon, C.; Puigserver, P.; et al. CREB regulates hepatic gluconeogenesis through the coactivator PGC-1. Nature 2001, 413, 179-183. [CrossRef]

38. Herzig, S.; Hedrick, S.; Morantte, I.; Koo, S.H.; Galimi, F.; Montminy, M. CREB controls hepatic lipid metabolism through nuclear hormone receptor PPAR- $\gamma$. Nature 2003, 426, 190-193. [CrossRef]

39. Houglum, K.; Lee, K.S.; Chojkier, M. Proliferation of hepatic stellate cells is inhibited by phosphorylation of CREB on serine 133. J. Clin. Investig. 1997, 99, 1322-1328. [CrossRef]

40. Ozcan, L.; Wong, C.C.; Li, G.; Xu, T.; Pajvani, U.; Park, S.K.; Wronska, A.; Chen, B.X.; Marks, A.R.; Fukamizu, A.; et al. Calcium signaling through CaMKII regulates hepatic glucose production in fasting and obesity. Cell Metab. 2012, 15, 739-751. [CrossRef]

41. Khambu, B.; Yan, S.; Huda, N.; Liu, G.; Yin, X.M. Autophagy in non-alcoholic fatty liver disease and alcoholic liver disease. Liver 2018, 2, 112-119. [CrossRef]

42. He, Y.; Ao, N.; Yang, J.; Wang, X.; Jin, S.; Du, J. The preventive effect of liraglutide on the lipotoxic liver injury via increasing autophagy. Ann. Hepatol. 2020, 19, 44-52. [CrossRef] [PubMed]

43. Yang, L.; Li, P.; Fu, S.; Calay, E.S.; Hotamisligil, G.S. Defective hepatic autophagy in obesity promotes ER stress and causes insulin resistance. Cell Metab. 2010, 11, 467-478. [CrossRef]

44. Zhou, R.; Yi, L.; Ye, X.; Zeng, X.; Qin, Y.; Zhang, Q.; Mi, M. Resveratrol ameliorates lipid droplet accumulation in liver through a SIRT1/ATF6-dependent mechanism. Cell. Physiol. Biochem. 2018, 51, 2397-2420. [CrossRef]

45. Deng, X.Q.; Chen, L.L.; Li, N.X. The expression of SIRT1 in nonalcoholic fatty liver disease induced by high-fat diet in rats. Liver Int. 2007, 27, 708-715. [CrossRef]

46. Nakadera, E.; Yamashina, S.; Izumi, K.; Inami, Y.; Sato, T.; Fukushima, H.; Kon, K.; Ikejima, K.; Ueno, T.; Watanabe, S. Inhibition of mTOR improves the impairment of acidification in autophagic vesicles caused by hepatic steatosis. Biochem. Biophys. Res. Commun. 2016, 469, 1104-1110. [CrossRef]

47. Kang, J.W.; Choa, H.I.; Lee, S.M. Melatonin inhibits mTOR-dependent autophagy during liver ischemia/reperfusion. Cell. Physiol. Biochem. 2014, 33, 23-36. [CrossRef]

48. Takahashi, K.; Yanai, S.; Shimokado, K.; Ishigami, A. Coffee consumption in aged mice increases energy production and decreases hepatic mTOR levels. Nutrition 2017, 38, 1-8. [CrossRef] [PubMed]

49. Salomone, F.; Galvano, F.; Li Volti, G. Molecular bases underlying the hepatoprotective effects of coffee. Nutrients 2017, 9, 85. [CrossRef] 
50. Zadernowski, R.; Naczk, M.; Nesterowicz, J. Phenolic acid profiles in some small berries. J. Agric. Food Chem. 2005, 53, $2118-2124$. [CrossRef] [PubMed]

51. Saiki, S.; Sasazawa, Y.; Imamichi, Y.; Kawajiri, S.; Fujimaki, T.; Tanida, I.; Kobayashi, H.; Sato, F.; Sato, S.; Ishikawa, K.; et al. Caffeine induces apoptosis by enhancement of autophagy via PI3K/Akt/mTOR/p70S6K inhibition. Autophagy 2011, 7, $176-187$. [CrossRef] [PubMed]

52. Refolo, M.G.; Lippolis, C.; Carella, N.; Cavallini, A.; Messa, C.; D'Alessandro, R. Chlorogenic acid improves the Regorafenib effects in human hepatocellular carcinoma cells. Int. J. Mol. Sci. 2018, 19, 1518. [CrossRef]

53. Yan, H.; Gao, Y.Q.; Zhang, Y.; Wang, H.; Liu, G.S.; Lei, J.Y. Chlorogenic acid alleviates autophagy and insulin resistance by suppressing JNK pathway in a rat model of nonalcoholic fatty liver disease. J. Biosci. 2018, 43, 287-294. [CrossRef] [PubMed]

54. Mukhopadhyay, P.; Horváth, B.; Rajesh, M.; Varga, Z.V.; Gariani, K.; Ryu, D.; Cao, Z.; Holovac, E.; Park, O.; Zhou, Z.; et al. PARP inhibition protects against alcoholic and non-alcoholic steatohepatitis. J. Hepatol. 2017, 66, 589-600. [CrossRef] [PubMed]

55. Gariani, K.; Ryu, D.; Menzies, K.J.; Yi, H.S.; Stein, S.; Zhang, H.; Perino, A.; Lemos, V.; Katsyuba, E.; Jha, P.; et al. Inhibiting poly ADP-ribosylation increases fatty acid oxidation and protects against fatty liver disease. J. Hepatol. 2017, 66, 132-141. [CrossRef] [PubMed]

56. Salomone, F.; Barbagallo, I.; Godos, J.; Lembo, V.; Currenti, W.; Cinà, D.; Avola, R.; D’Orazio, N.; Morisco, F.; Galvano, F.; et al. Silibinin restores $\mathrm{NAD}^{+}$levels and induces the SIRT1/AMPK pathway in non-alcoholic fatty liver. Nutrients 2017, 9, 1086. [CrossRef]

57. Li, Y.; Chen, Y.; Huang, H.; Shi, M.; Yang, W.; Kuang, J.; Yan, J. Autophagy mediated by endoplasmic reticulum stress enhances the caffeine-induced apoptosis of hepatic stellate cells. Int. J. Mol. Med. 2017, 40, 1405-1414. [CrossRef]

58. Wang, Z.; Gu, C.; Wang, X.; Lang, Y.; Wu, Y.; Wu, X.; Zhu, X.; Wang, K.; Yang, H. Caffeine enhances the anti-tumor effect of 5-fluorouracil via increasing the production of reactive oxygen species in hepatocellular carcinoma. Med. Oncol. $2019,36,97$. [CrossRef]

59. Chen, J.C.; Hwang, J.H.; Chiu, W.H.; Chan, Y.C. Tetrandrine and caffeine modulated cell cycle and increased glioma cell death via caspase-dependent and caspase-independent apoptosis pathways. Nutr. Cancer 2014, 66, 700-706. [CrossRef]

60. Zhang, Y.; Miao, L.; Zhang, H.; Wu, G.; Zhang, Z.; Lv, J. Chlorogenic acid against palmitic acid in endoplasmic reticulum stress-mediated apoptosis resulting in protective effect of primary rat hepatocytes. Lipids Health Dis. 2018, 17, 270. [CrossRef]

61. Heimbach, J.T.; Marone, P.A.; Hunter, J.M.; Nemzer, B.V.; Stanley, S.M.; Kennepohl, E. Safety studies on products from whole coffee fruit. Food Chem. Toxicol. 2010, 48, 2517-2525. [CrossRef]

62. Halvorsen, B.L.; Carlsen, M.H.; Phillips, K.M.; Bøhn, S.K.; Holte, K.; Jacobs, D.R.; Blomhoff, R. Content of redox-active compounds in foods consumed in the United States. Am. J. Clin. Nutr. 2006, 84, 95-135. [CrossRef]

63. Duangjai, A.; Nuengchamnong, N.; Suphrom, N.; Trisat, K.; Limpeanchob, N.; Saokaew, S. Potential of coffee fruit extract and quinic acid on adipogenesis and lipolysis in 3T3-L1 adipocytes. Kobe J. Med. Sci. 2018, 64, E84-E92.

64. Vitaglione, P.; Morisco, F.; Mazzone, G.; Amoruso, D.C.; Ribecco, M.T.; Romano, A.; Fogliano, V.; Caporaso, N.; D’Argenio, G. Coffee reduces liver damage in a rat model of steatohepatitis: The underlying mechanisms and the role of polyphenols and melanoidins. Hepatology 2010, 52, 1652-1661. [CrossRef]

65. Vistisen, K.; Poulsen, H.E.; Loft, S. Foreign compound metabolism capacity in man measured from metabolites of dietary caffeine. Carcinogenesis 1992, 13, 1561-1568. [CrossRef] [PubMed]

66. Devasagayam, T.P.; Kamat, J.P.; Mohan, H.; Kesavan, P.C. Caffeine as an antioxidant: Inhibition of lipid peroxidation induced by reactive oxygen species. Biochim. Biophys. Acta. 1996, 1282, 63-70. [CrossRef]

67. Sharp, D.S.; Benowitz, N.L. Re: "Alcohol, smoking, coffee, and cirrhosis" and "coffee and serum gamma-glutamyltransferase: A study of self-defense officials in Japan". Am. J. Epidemiol. 1995, 141, 480-481. [CrossRef]

68. Sinha, R.A.; Farah, B.L.; Singh, B.K.; Siddique, M.M.; Li, Y.; Wu, Y.; Ilkayeva, O.R.; Gooding, J.; Ching, J.; Zhou, J.; et al. Caffeine stimulates hepatic lipid metabolism by the autophagy-lysosomal pathway in mice. Hepatology 2014, 59, 1366-1380. [CrossRef] [PubMed] 